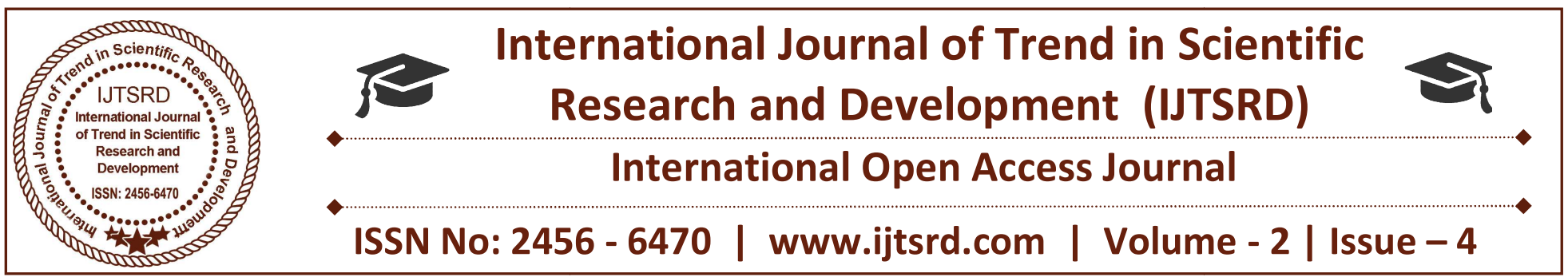

\title{
Cryptocurrency - Few Words on Digital Money
}

\author{
Prasanta Kumar Dey \\ Associate Professor, Department of Commerce, Sir Gurudas Mahavidyalaya, Ultadanga, \\ Kolkata, West Bengal, India
}

\begin{abstract}
Cryptocurrency, a new technology depended electronic currency, is seemed as business commodity for investment and medium of exchange to few number of people of the world. It has different forms in different countries even more different forms in the same country. Bit coin, the first and most popular cryptocurrency, is paving the way as a disruptive technology to long standing and unchanged financial payment systems that have been in place for many decades. In some countries, cryptocurrency has been recognized by the respective governments. While cryptocurrencies are not likely to replace traditional fiat currency, they could change the way internetconnected global markets interact with each other, clearing away barriers surrounding normative national currencies and exchange rates. Cryptocurrencies bear both some advantages and disadvantages in uses.
\end{abstract} Over the last few years, it has been gaining rapid popularity in the public eye. In India, recognition process has been started to come into mainstream of the public domain. In this article, a short analysis of cryptocurrency is presented, which illuminates some of the recent events and movements that could influence whether cryptocurrency contributes to a shift in economic paradigms. The article covers the original idea and motivation, the mode of operation and possible applications of Cryptocurrencies and block chain technology. We conclude the article mentioning the prospect of cryptocurrency in India as well as in the world.

Keywords: Block Chain, Bit coin, Cryptocurrency, Virtual Currency, Wallets

Concept of Cryptocurrency - The word 'Crypto' originates from Greek word "Krypto". In noun meaning, it denotes a person who secretly supports or

adheres to a group, party or belief. In adjective meaning, it denotes hidden, secret, concealed and not publicly admitted. Here may be used in the formation of compound words such as cryptography, crypto programs, crypto people, crypto fascist, crypto communist, cryptocurrency etc. A cryptocurrency (or cryptocurrency) is secret currency or hidden currency and so on. In the present day scenario, it is a digital currency or digital money or electronic money or electronic currency designed to work as a medium of exchange. It is a type of currency available in digital form, e-cash, not in physical form such as banknotes and coins. ifi It uses cryptography to secure its transactions to control the creation of additional units and to verify the transfer of assets. Cryptocurrencies are a type of digital currencies, alternative currencies and virtual currencies. Cryptocurrencies use decentralized control as opposed to centralized electronic money and central banking systems. The decentralized control of each crypt currency works through a block chain which is a public transaction database, functioning as a distributed ledger. Cryptocurrency is issued and usually controlled by its developers and used and accepted the members of a specific virtual community.

According to Jan Lansky, a cryptocurrency is a system that meets all of the following six conditions:

1. The system does not require a central authority, distributed achieve consensus on its state.

2. The system keeps an overview of cryptocurrency units and their ownership.

3. The system defines whether new cryptocurrency units can be created. If new cryptocurrency units can be created, the system defines the 
circumstances of their origin and how to determine the ownership of these new units.

4. Ownership of cryptocurrency units can be proved exclusively cryptographically.

5. The system allows transactions to be performed in which ownership of the cryptographic units is changed. A transaction statement can only be issued by an entity proving the current ownership of these units.

6. If two different instructions for changing the ownership of the same cryptographic units are simultaneously entered, the system performs at most one of them.

It exhibits properties similar to physical currencies but allows for instantaneous transactions and borderless transfer-of-ownership. Examples include virtual currencies and Cryptocurrencies or even central bank issued digital based money. Like traditional money, these currencies may be used to buy physical goods and services but may also be restricted to certain communities such as for use inside an online game or social network. Digital currency is a money balance recorded electronically on a stored-value card or other device. Another form of electronic money is network money allowing the transfer of value on computer networks particularly the internet. Electronic money is also a claim on a private bank or other financial institution such as bank deposits. Digital money can either be centralized where there is a central point of control over the money supply or decentralized where the control over the money supply can come from various sources.

Genesis of cryptocurrency - In 1983, a research paper by David Chaum introduced the idea of digital cash. In 1990, he founded DigiCash, an electronic cash company, in Amsterdam to commercialize the ideas in his research. It filed for bankruptcy in 1998. In 1999, Chaum left the company. In 1997 , Coca-Cola offered buying from vending machines using mobile payments. After that PayPal emerged in 1998. Other system such as e-gold followed suit, but faced issues because it was used by criminals and was raided by US Feds in 2005. In 2009, bit coin was introduced which marked the start of digital currencies. Origins of digital currencies date back to the 1990s Dot-com bubble. One of the first was e-gold founded in 1996 and backed by gold. Another known digital currency service providing company Liberty Reserve was founded in 2006. It let users to convert dollars or euros to Liberty Reserve Dollars or Euros and exchange them freely with one another at a $1 \%$ fee. Both services were centralized and reputed to be used for money laundering and inevitably shut down by the U.S. Government. Q coins or QQ coins were used as a type of commodity-based digital currency on Tencent QQ's messaging platform and emerged in early 2005. Q coins were so effective in China that they were said to have had a destabilizing effect on the Chinese Yuan currency due to speculation. Recent interest in Cryptocurrencies has prompted renewed interest in digital currencies, with bitcoin introduced in 2009 becoming the most widely used and accepted digital currency.

Advantages of use of cryptocurrency - The benefits of digital currency are plenty in numbers. Not only is it good for the business or the business owner but the buyer themselves. Of course if one purchases a specific crypto and it has shot up in price, him / her buying using pennies on the dollar. In the long term, it definitely pays off. Beside this, the added advantages may be summed up as follows:

1. Easy access - Cryptocurrency is readily available to the general public. Almost anyone can make use of it. It is a decentralized operation and investors from all over the world have easy access to them. You can find various projects trying to raise funds through cryptocurrency. Almost anyone that can make online fund transfers can become part of such projects.

2. Quick and easy payments - Making payments using cryptocurrency is very easy. You can do it in just a matter of a few seconds. It is very fast because you don't require feed many details, you don't even need to enter your debit / credit card details. All you need is the address of the wallet of the person or enterprise to which you wish to make the payment too. The amount shall credit to the receiver within few seconds to a few minutes depending on the crypto. The ease of transfer and the low transaction fees makes it very desirable.

3. Fast settlements - With crypto, you don't need to wait a couple days for your business to receive the money. Due to the technology, Cryptocurrencies are based on the block chain it removes delays, payment of fees and a host of other third party approval that might have been present. For traditional businesses, there are often hiccups and bottlenecks due to the number of middlemen that you have to cut through. With cryptocurrency transactions, there is a quick settlement as the 
peer-to-peer nature of the networking structure cuts off the middleman. Crypto contracts were designed to eliminate the bottlenecks that have come to characterize traditional settlement. The settlement is immediate and can be completed for a fraction of time and expense that it would have taken a traditional transfer.

4. Lower fees - We've all been there and sometimes it could be painful just to view your monthly account statements from your bank. You'll often be shocked at the number of fees chalked up. Transferring money by using any other online forum or bank gateway is expensive as they levy considerable fees for the transaction. Credit card processing companies charge hefty fees. But it is not the case with cryptocurrency as the costs are nil or negligible. With credit cards or debit cards, the seller is the one paying a fee but for crypto's, it is the buyer paying the small fee. The issue with these fees is that they often pile up and could quickly pile up. Transaction fees are very miniscule and only the buyer gets hit with it.

5. More confidential - You don't need to share your identity or whereabouts or the details of the transactions made between you and the beneficiary. No information is required to share with the government and the bank regarding the deal. It is truly decentralized.

6. Highly secured-All your transactions will be secure as it is using NSA created cryptograph.

It is next to impossible for any person other than the owner of the wallet to make any payment from the wallet unless they were hacked which there many ways to protect you from are.

7. Remain anonymous - Some coins can help you stay anonymous but contrary to popular belief, not all of them can. Bit coin is pseudonymous which means people won't know exactly who you are on the block chain but they can get some information from it.

8. Identity theft - Nobody can steal your personal information from merchants, which ensures the privacy of your sensitive data. By creating a proxy ID, you can make sure that no one knows anything about you. Among the benefits that come from using cryptocurrency is the protection of your online identity. Using the old fiat method requires providing your credit card information to a merchant who gets to access every detail through the "pull" basis where the card pulls out your details before debiting your account. With cryptocurrency transactions, it is almost impossible for your private key to be found or hacked unless you're not smart about it.

9. No chargeback - Once you made the payment, you cannot chargeback. This considerably depletes the chances of a fraud. Once the transfer has completed, it cannot reverse. Nobody can file chargeback like you can on credit cards. It has its cons but can be a benefit also.

10. No third party - You are the master of your money. You can keep it in your wallet and use it as per your wishes. There is no third party involved like a bank on whom you need to trust.

11. Facilitate international trades-When you talk about transactions using Cryptocurrencies then there are no limits. You may be in a different part of the world and the receiver might be in some other hemisphere, you can still transfer the amount without any hassle. The inter-country transaction is extremely easy with cryptocurrency because its function is not under the control of any central bank. This makes it easier for users to transact with it without having levies imposed on them or have their value reduced by exchange rates. This makes it quite suitable for cross-border transfers without any form of hindrance.

Disadvantages of use of cryptocurrency - Many of existing digital currencies have not yet seen widespread usage and may not be easily used or exchanged. Banks generally do not accept or offer services for them. There are concerns that Cryptocurrencies are extremely risky due to their very high volatility and potential for pump and dump schemes. Regulators in several countries have warned against their use and some have taken concrete regulatory measures to dissuade users. All the advantages do not mean that there are no risks involved in investing in Cryptocurrencies. Just like anything else financially, they are not perfect and there are drawbacks of Bit coin. Here we will discuss some disadvantages of Cryptocurrencies:

1. Difficult to understand-Cryptocurrencies are relatively new and come with a learning curve. People end up investing without proper knowledge and lose money to something they did not learn about.

2. Lack of knowledge - People is often not aware of how to use cryptocurrency and hence open themselves to hacker. The technology is somewhat complex and therefore one needs to be mindful of it before investing. 
3. Not accepted widely - Not many websites and companies accept digital currencies yet. Very few countries have legalized the use of Cryptocurrencies. It makes it impractical for everyday use. Due to lack of acceptance, before buying or investing online, you need to make sure that it's accepted at that place where you want to use it. Although it is slowly getting the acceptance around the world, it will take time to take the idea entirely out of the shadows. While popular cryptocurrency such as bit coin is currently being used in different ways, there is still a long way to go for it to be used for commerce, international bank transfers as well as electronic payments. For cryptocurrency to get to this level, smart and scalable applications will need to be built for handling the wide scale of money transfer as well as micropayment services.

4. Can lose your wallet - There is a possibility of losing your wallet. If you have stored the money in the form of digital currency on your phone or computer, you better remember your password and not lose those devices. Losing your coins means you won't be able to retrieve it, even with the help of legal assistance so that is just one of bit coin flaws.

5. No way to reverse the payment - If you mistakenly pay someone by using cryptocurrency, then there is any way to get a refund of the amount paid. All you can do is to ask the person for a refund and if your request is turned down, then just forget about the money.

6. Uncertainty and Volatility - Since Cryptocurrencies are so new, they are also very volatile. This is one of the main reasons mass adoption is taking longer than it should. Many corporations don't want to deal with a form of money that is going to go through huge swings in volatility.

7. Scaling - Based on the way smart contracts are designed, there is a limit to the speed and number of transactions it can process at a time which has hindered the widespread adoption of digital currencies. With the introduction of lightning networks, the crypto community has put a foot in the right direction which gives breathes hope into the idea that cryptocurrency could one day replace conventional credit card transactions.

Present scenario of Cryptocurrencies in different countries - The number of Cryptocurrencies available in the world over the internet as on
10 April, 2018 is over 1,565 and growing. A new cryptocurrency can be created at any time. By market capitalization, Bit coin is currently the largest block chain network followed by Ethereun, Ripple, Bit coin Cash, Cardano, Stellar, Litecoin, EOS, NEO and NEM. Over 24 countries are investing in distributed ledger technologies (DLT) with $\$ 1.4$ bn in investments. In addition, over 90 central banks are engaged in DLT discussions, including implications of a central bank issued digital currency. A few of them are being highlighted as below:

1. Hong Kong's Octopus card system - Launched in 1997 as an electronic purse for public transportation is the most successful and mature implementation of contactless smart cards used for mass transit payments. After 5 years, 25 percent of Octopus card transactions are unrelated to transit and accepted by more than 160 merchants.

2. London Transport's Oyster card - Oyster is a plastic smart card which can hold pay as you go credit, Travel cards and Bus \& Tram season tickets. You can use an Oyster card to travel on bus, Tube, tram, DLR, London over ground and most National Rail services in London.

3. Japan's Felica - A contactless RFID smart card used in a variety of ways such as in ticketing systems for public transportation, e-money and residence door keys.

4. Netherlands' Chipknip - As an electronic cash system used in the Netherlands, all ATM cards issued by the Dutch banks had value that could be loaded via Chipknip loading stations. For people without a bank, pre-paid Chipknip cards could be purchased at various locations in the Netherlands. The Dutch Central Bank is experimenting with a bit coin-based virtual currency called "DNB Coin".

5. Belgium's Proton - An electronic purse application for debit cards in Belgium was introduced in February 1995, as a means to replace cash for small transactions. The system was retired in December 31, 2014.

6. Canada - The Bank of Canada explored the possibility of creating a version of its currency on the block chain. The Bank of Canada teamed up with the nation's five largest banks and the block chain consulting firm R3 for what was known as Project Jasper. In a simulation run in 2016, the central bank issued CAD-Coins onto a block chain similar Ethereum. The banks used the CAD-Coins 
to exchange money the way they do at the end of each day to settle their master accounts.

7. China - A deputy governor at the central bank of China, Fan Yifei, wrote that "the conditions are ripe for digital currencies which can reduce operating costs, increase efficiency and enable a wide range of new applications." According to Fan Yifei, the best way to take advantage of the situation is for central banks to take the lead, both in supervising private digital currencies and in developing digital legal tender of their own.

8. Denmark - The Danish government proposed getting rid of the obligation for selected retailers to accept payment in cash, moving the country closer to a "cashless" economy. The Danish Chamber of Commerce is backing the move. Nearly one third of the Danish population uses Mobile Pay, a smart phone application for transferring money.

9. Ecuador - A law passed by the National Assembly of gives the government permission to make payments in electronic currency and proposes the creation of a national digital currency. "Electronic money will stimulate the economy; it will be possible to attract more Ecuadorian citizens, especially those who do not have checking or savings accounts and credit cards alone. The electronic currency will be backed by the assets of the Central Bank of Ecuador," the National Assembly said in a statement. In December 2015, Sistema de Dinero Electrónico ("electronic money system") was launched, making Ecuador the first country with a state-run electronic payment system.

10. Germany - The German Central Bank is testing a functional prototype for the block chain technology-based settlement of securities and transfer of centrally-issued digital coins.

11. Russia - Government-controlled Sberbank of Russis owns Yandex Money - electronic payment service and digital currency of the same name. Russia's President Vladimir Putin has signed off on regulation of ICOs and cryptocurrency mining by July 2018.

12. South Korea - South Korea plans national digital currency using a block chain. The chairman of South Korea's Financial Services Commission (FSC), Yim Jong-yong, announced that his department will "Lay the systemic groundwork for the spread of digital currency." South Korea has already announced plans to discontinue coins by the year 2020 .
13. Sweden - Sweden is in the process of replacing all of its physical banknotes and most of its coins by mid 2017. However the new banknotes and coins of the Swedish Krona will probably be circulating at about half the 2007 peak of 12,494 kronor per capita. The Risk bank is planning to begin discussions of an electronic currency issued by the central bank to which "is not to replace cash, but to act as complement to it." Deputy Governor Cecilia Skingsley states that cash will continue to spiral out of use in Sweden, and while it is currently fairly easy to get cash in Sweden, it is often very difficult to deposit it into bank accounts, especially in rural areas. No decision has been currently made about the decision to create "e-krona". In her speech Skingsley states: "The first question is whether e-krona should be booked in accounts or whether the ekrona should be some form of digitally transferable unit that does not need an underlying account structure, roughly like cash." Skingsley also states that: "Another important question is whether the Riks bank should issue e-krona directly to the general public or go via the banks, as we do now with banknotes and coins." Other questions will be addressed like interest rates, should they be positive, negative, or zero?

14. Switzerland - In 2016, a city government first accepted digital currency in payment of city fees. Zug Switzerland added bit coin as a means of paying small amounts, up to $200 \mathrm{SFr}$. in a test and an attempt to advance $\mathrm{Zug}$ as a region that is advancing future technologies. In order to reduce risk, Zug immediately converts any bit coin received into the Swiss currency. Swiss Federal Railways, government-owned railway company of Switzerland, sells bit coins at its ticket machines.

15. UK - The Chief Scientific Adviser to the UK government advised his Prime Minister and Parliament to consider using a block chain-based digital currency. The chief economist of Bank of England, the central bank of the United Kingdom, proposed abolition of paper currency. The Bank has also taken an interest in bit coin. In 2016, it has embarked on a multi-year research programme to explore the implications of a central bank issued digital currency. The Bank of England has produced several research papers on the topic. One suggests that the economic benefits of issuing a digital currency on a distributed ledger could add as much as 3 percent to a country's economic output. 
16. Ukraine - The National Bank of Ukrain is considering a creation of its own issuance / turnover / servicing system for a block chainbased national cryptocurrency. The regulator also announced that block chain could be a part of a national project called "Cashless Economy".

Cryptocurrency in India - In India, a cryptocurrency platform has already been developed with the name "Indiacoin" in 2017. Mumbai based payment gateway Billdesk has launched 'Coinome', India's first cryptocurrency exchange. Coinome will allow users to be on-boarded via Instant e-KYC. Users can start transacting in cryptocurrencies almost immediately upon registering. The exchange supports instant deposits using payment gateway and instant withdrawals, thereby allowing transactions even on weekends or business holidays. The exchange plans to support 20 mainstream cryptocurrencies by 2018. Till to date, the government of India has not yet approved any transaction through cryptocurrencies. But, the Government has said we need to analysis it before approval. Recently, finance minister Arun Jaitley said that India does not recognize cryptocurrency as legal tender 'as of now'. "Recommendations are being worked at. The government's position is clear, we don't recognize this as legal currency as of now," Jaitley said when asked whether the government has taken any decision on cryptocurrency. Jaitley though confirmed that the Department of Economic Affairs (DEA) had constituted a committee with representations from DEA, Department of Financial Services (DFS), Ministry of Home Affairs (MHA), RBI, Niti Aayog and SBI and it has submitted its report. The report is being examined, he said. Earlier in August, during the monsoon session of parliament, the finance minister had informed that there are no regulations governing virtual currencies, including bitcoins, in India and the RBI has not given any license to any entity/company to operate such currencies. It is approved by the Japan Government. China Government is planning to adapt ethereum technology whereas Russia is planning to create its own crypto. USA is positive about it. So the decision from other countries will definitely influence the Indian Government

Guidelines to crypto world - If you are new to handle with any cryptocurrency, then these guidelines may help you in all the right directions while making you aware of the many pitfalls that exist. There are different ways to achieve the same outcomes from the different block chains of Cryptocurrencies. Almost some common steps for safe entry into the crypto world are being discussed here. These are your first steps into the crypto world, a step-by-step guide which will safely guide you through the whole process, from opening your account with the crypto exchange to buying and selling the Cryptocurrencies.

The steps are:

1. Registering for crypto account - To operate with any form of cryptocurrency, you will first need to open an account on the online exchange. There are several online exchanges through which you can carry out the task at hand for well established service in compliance with the highest legal and safety standards in the crypto world.

2. Verifying crypto account - After having successfully opened an account, it is now mandatory to carry out the security verification of personal information. If you have logged into Bit stamp, say, right after the previous steps of changing your password, you will be welcomed to your account with a confirmation: You have successfully changed your password. Followed by: To verify your account, please click here. Click HERE to enter the verification options.

3. Enabling the two-factor authentication - It is highly recommended you to enable the two-factor authentication system which will significantly increase the security of your account and transactions. After enabling this service, you will always be asked to confirm your login and transactions with an additional security code from your smart mobile tablet device.

4. Depositing fund on your crypto account - Your crypto account is now registered, verified and protected and thereby ready for safe deposit. After logon the crypto account with any exchange, by default, the account is set to operate with the currencies and so first it will have to change the currencies.

5. Exchanging funds into cryptocurrency - Now you have EUR, say, on your crypto account and you will exchange EUR to the cryptocurrency ETH, say, and go on trading as per block chain.

Prospect of use of cryptocurrency - Over the last couple of years, the term cryptocurrency has been rapidly gaining ground and understanding its use and value in the public eye. At first it seemed unfamiliar and somewhat scary like the credit card looked to users in its early days. You might be more familiar with terms like bit coin and Ether. These are all 
Cryptocurrencies using the block chain technology to keep this currency and technology safe. Currently, there are many types of Cryptocurrencies. A simple Google search of the popular trend shows you the start of the growth and where it is taking us. Cryptocurrencies have been drawing significant interest over the last several years according to Charles Bovaird, a financial writer and consultant who has worked for State Street, Moody's and Citizens Commercial Banking. He currently holds bit coin and Ether, two leading types of digital currency and believes that the future is bright for digital currencies. "This growing visibility is evident in both Google trends search data and also the rising market values of the digital currencies themselves," he said. Zack Friedman, founder and CEO of Make Lemonade whose career has included stints as CFO of a global energy company, hedge fund investing and jobs with The Blackstone Group and Morgan Stanley, said Cryptocurrencies have undisputed advantages but a uncertain future. "Proponents of Cryptocurrencies cite several key advantages, namely decentralization, anonymity, security and automation," Friedman said. "However, investors are split regarding the stability and merits of Cryptocurrencies, with some believing they represent the wave of the future, while others dismiss them as pure speculation."

Conclusion - Many of existing digital currencies have not yet seen widespread usage and may not be easily used or exchanged. Banks generally do not accept or offer services for them. There are concerns that Cryptocurrencies are extremely risky due to their very high volatility and potential for pump and dump schemes. Regulators in several countries have warned against their use and some have taken concrete regulatory measures to dissuade users. The non-Cryptocurrencies are all centralized. As such, they may be shut down or seized by a government at any time. The more anonymous a currency is, the more attractive it is to criminals, regardless of the intentions of its creators. Forbes writer Tim Worst all has written that the value of bit coin is largely derived from speculative trading. Bit coin has also been criticized for its energy inefficient SHA-256-based proof of work. As of now, cryptocurrency has no significant reception which is a major drawback but slowly and steadily it is consolidating its position. Both developed as well as developing countries are legalizing and regulating the use of cryptocurrency in some way or another. Even countries with a high political restriction like Russia and China are trying to make it so people can be able to freely spend them. We can already see bit coins effect on the economy. It is very large and only growing at an outstanding rate. Singapore and Switzerland are the most advanced countries in the use of cryptocurrency as of now. Clearly, the advantages do overcome the disadvantages and this is the reason why the base of cryptocurrency is increasing. After seeing the benefits of using cryptocurrency, people are more than willing to accept the risks involved. This article will help you to form a better perspective on its use. Like anything else, there are few shortcomings but the positive aspects outshine the drawbacks. With everything in life, there are always pros and cons and this is why you need to weigh both actions thoroughly before making a decision. For cryptocurrency, its ascension has been due to its ability to initiate secure and untraceable transactions. Now, that the technology is here, only time will tell if the rest of the world will accept it.

\section{REFERENCES}

Books

1. Antonopoulos, Andres M (2016), The Internet of Money: Talks, Merkle Bloom LLC

2. Casey, Michael J. and Vigna, Paul (2016), Cryptocurrency - The Age of Cryptocurrency, Random House

3. Aarya, Ravin (2017), Barter to Bit coin, Paperback

4. Anderson, Jamesh C. (2017), Kindle Edition

Articles

1. King, R. S. (2013, December 17), By reading this article, you "re mining bit coins. Retrieved from Quartz.com Website: http://qz.com/154877/byreading-this-page-you-are-mining-bitcoins

2. Kelly, B (2014), The Bit coin Big Bang : How Alternative Currencies Are About to Change the World

3. McMillan, R. (2014, March 3). The Inside Story of Mt. Gox, Bit coin "s \$460 Million Disaster. Retrieved from Wired.com Website: http://www.wired.com/2014/03/bitcoin-exchange

4. Bit coin: A New Global Economy. (2015, August 4). Retrieved July 2016, from Bit Pay, Inc. Website: https://blog.bitpay.com/bitcoin-a-newglobal-economy 
International Journal of Trend in Scientific Research and Development (IJTSRD) ISSN: 2456-6470

5. DeVrise, Peter D., An Analysis of 9. From Wikipedia Articles, the free encyclopedia Cryptocurrency, Bit coin and the Future, Websites International Journal of Business Management and Commerce (September 2016), Vol. 1 No. 2,

- www.okex.com/bitcoin/exchange

6. McHardie, Ken, The Strengths and Weaknesses of Bit coin, Published on January 2018 in Bitcoin Block chain, Cryptocurrency, digital currency

7. Berentsen, Aleksender and Scha, Fabian, A Short Introduction to the World of Cryptocurrencies, Federal Reserve Bank of St. Louis Review, First Quarter 2018, 100(1), pp-1-16. https: doi.org/10. 20955/r.2018.1-16

8. Chiu, J., and T. Wong. (2014). "E-Money:

- www.deribit.com/Bitcoin/Trading

- www.quora.com

- www.zapmeta.co.in

- www.Verasity.io/Crypto_ICO

- www.blockonomi.com

- www.chapman.edu/research/institutes - and .... papers/ Efficiency, Stability and Optimal Policy.” Bank of Canada Working Paper No. 2014-16. 